\title{
Dynamic model of a solar powered absorption refrigeration system
}

\author{
A. Gómez-Moreno¹, J.M. Palomar-Carnicero, F. Cruz-Peragón \\ ${ }^{1}$ Department of Mechanical and Mining Engineering \\ E.P.S. of Jaén, University of Jaén \\ Paraje Las Lagunillas, s/n - Edificio A3, 23071 Jaén (España) \\ Telephone/Fax: +0034 953212903, e-mail: agmoreno@ujaen.es
}

\begin{abstract}
This paper focuses on the analysis of a dynamic simulation model used to describe the operation of a solar cooling system located in Jaén (Spain). The dynamic model has been developed using the simulation environment TRNSYS.

The main goal of this paper has been to analyze separately the dynamic behaviour of each components of the installation and have been shown the differences between the temperatures of input and output of each of them, discussing and justifying the phenomena that appear. During the analysis phase and using and detailed model of the solar cooling system, it has been dedicated a special interest in showing the differences in all components between the initial transitional period and the period of stabilization of their operation.
\end{abstract}

\section{Key words}

Modeling, Dynamic, Solar, Cooling, Absorption.

\section{Introduction}

In recent years, the rising costs of energy and the recent political acceptance of the new version that prescribes that all new buildings must be "nearly zero- energy buildings" by 2020 [1]. It has caused great attention to design more efficient heating, ventilation, and air conditioning (HVAC) system of buildings in order to reduce consumption. All these developments have contributed to an increased use of solar energy to cover the demands of heating and cooling individual homes or office buildings [2].

The cooling demands are met by conventional cooling machines for operate require electricity consumption. The widespread use of these devices causes technical problems in seasons like summer in which its use is concentrated [3].

However, an alternative to conventional refrigeration equipment is the use of absorption chillers. One of the main advantages of these devices is that they consume less electricity and require heat for its operation that can provided from solar energy, in addition solar radiation is abundant in these periods [4]. Thus, cooling is a particularly attractive application for solar energy because of the simultaneous peak in cooling loads coincide with the availability of solar power $[5,6]$.

There are research literature referred to theoretical studies [5,7-9]. However, the material on numerical modeling studies is scarce [10]. One reason is that there are not many tools available for dimensioning solar cooling systems with absorption machines and there are no manuals that explain how to dynamically model these systems [11].

The main objective to be pursued with performing of this work has been modeling in TRNSYS, a program of thermal simulations, a real solar cooling system located at the University of Jaen, to make simulations that allow us more accurately understand its operation. The methodology described can be used to facilitate decision regarding possible future improvements in the design.

\section{Description of the system}

The system is formed by a single effect lithium bromide absorption chiller 4,5 kW (Rotartica 045 [12]), two hot water storage tank, one auxiliary boiler, one dry cooling tower and one fan coil. The dry cooling tower evacuates the residual heat from the condenser and the absorber to the outdoor air, and there is no need of a wet refrigeration tower.

The system has 3 different circuits. The generator circuit, the circuit of the evaporator (chilled water) and the condenser-absorber circuit (cooling water).The flow in each water circuit was held constant while the absorption chiller was in operation. The values recorded for the generator, evaporator and condenser-absorber water circuits were 17,216 l/min, 26,414 l/min and 39,438 $1 /$ min, respectively. Furthermore an additional circuit, the solar circuit, which provide heat to the generator circuit if there are usable solar radiation.

The system works from 8:00 to 18:00, Monday to Friday, outside these hours the installation was never put into operation. 


\section{Simulation model}

A model of the installation has been developed in TRNSYS software tool [13]. Figure 1 shows the flow chart of the installation. For installation modeling it have been used a Type developed in TRNSYS for each of them. For the room simulation, a TRNSYS type 56 component was used in the model. To develop the required information for the type 56, the TRNSYS application, TRNBUILD was used. Type 5 has been used to simulate cooling coil. Type1b for flat collector and Type 4 for Tanks have been used. The absorption chiller has been modeled using Type 107.
Since this type uses a catalogue data lookup approach to predict the output of the absorption chiller, it has been modified the file by entering the manufacturer's catalog data. An auxiliary heater with 13,5 kW has been modeled using Type6. Finally the dry cooling tower has been modeled using Type92.

Once the whole model was finished, it was simulated in TRNSYS with the following parameters:

- Simulation step time: $5 \mathrm{~min}$

- Tolerance integration: 0.01

- Tolerance convergence: 0.01

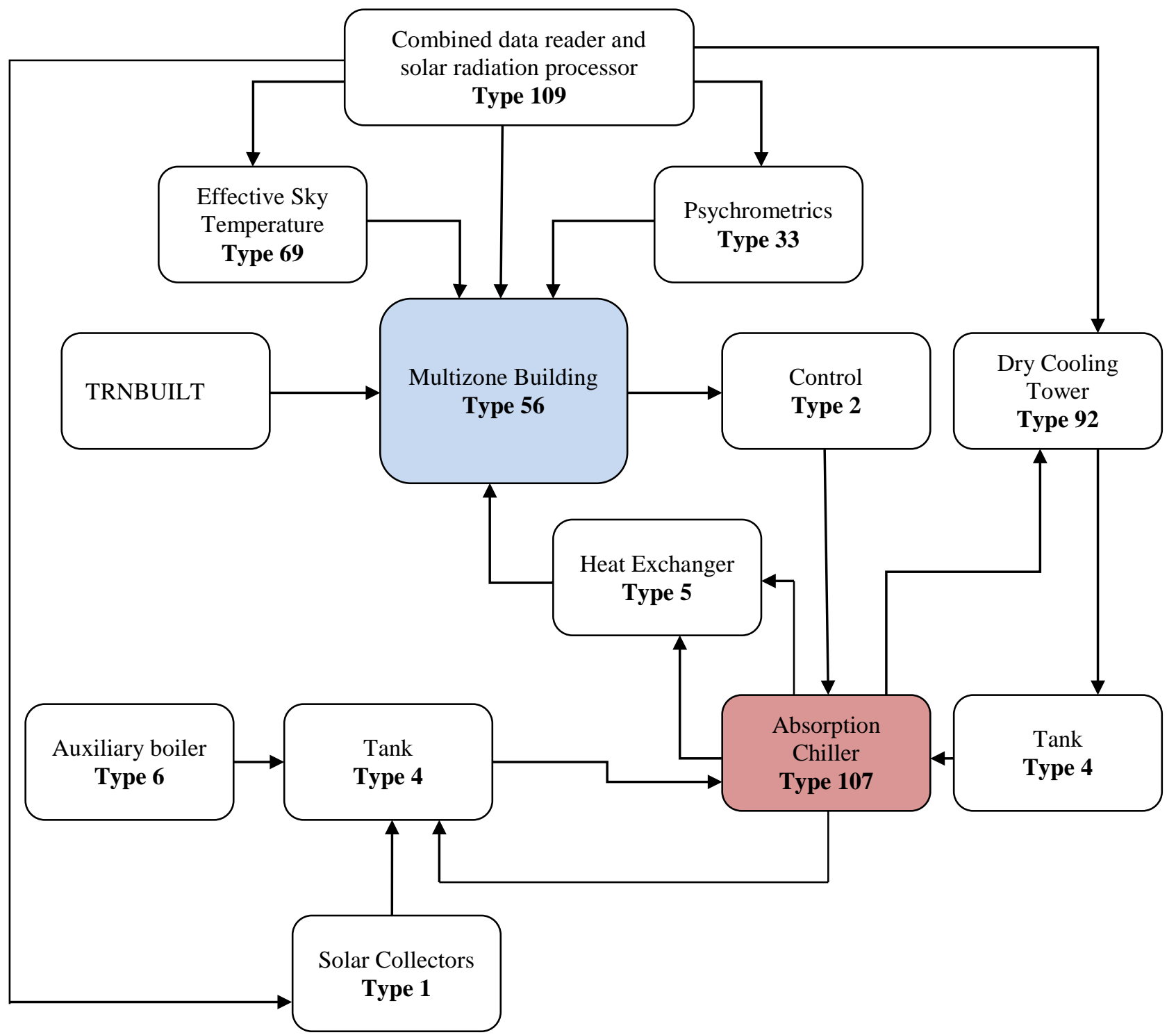

Fig. 1 Flow chart of the solar cooling system modeled in TRNSYS

\section{Results and discussion}

Along this section, the obtained results by simulation the operation of the components of the system will be discussed. An analysis of the phenomena occurring in different components of the system for a selected day will be conducted.

The analysis is performed for the weather conditions of June 6th, which corresponds with the hours 3792 to 3816.
This day has been selected because there were no clouds and it was a day of high temperature, so can be observed different effects on each of the components in a clear way avoiding dispersion would lead clouds

\section{A. Operation of the control elements}

The operation of the system is governed by two main controls. The first one will control the installation 
according to schedule, that if is necessary, it will run the installation from 8:00 to $18: 00$, Monday to Friday, outside these hours the installation was never put into operation. The second control is based on the temperature objective we want to achieve in the room. If the room temperature is higher than the target temperature, the installation will start operating, provided if it is within the above defined schedule. To enable installation or not, the controls send operating signals to the absorption chiller and pumps of the three circuits, actuating them or not as required.

Inside the generator there is another important control circuit to be described. It is the control of the solar circuit. This control does not affect the overall operation of the installation, but if the operating mode. This control is made in turn by two, the first one detected in a sense if the solar collector receives or not enough solar radiation to heat the fluid, i.e., it will compare the temperatures in and out the collector, so if the inlet temperature of the collector is lower than the output, control signal is equal to 1 . The other control determines whether the heat provided by the solar collector is sufficient for them are compared inlet temperature to heat exchanger from the solar collector to the inlet temperature to the heat exchanger from the generator circuit of the absorption machine. Thus the solar circuit will work only when it is profitable.

Finally it has been introduced a control in the three-way valve to conduct a bypass to the solar tank when this temperature is below of the temperature absorption chiller out. For efficient operation of the system, all controls have tolerances between 4 and 1 degrees. With this we avoid that the equipment are constantly turning off and on.
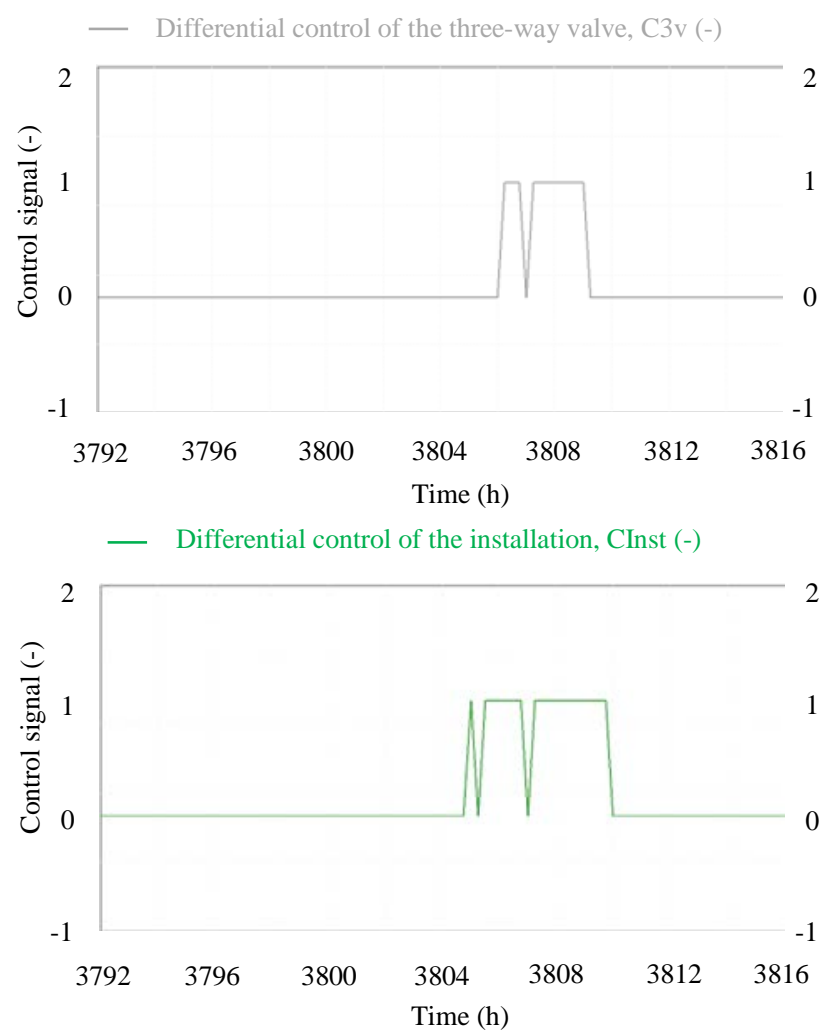

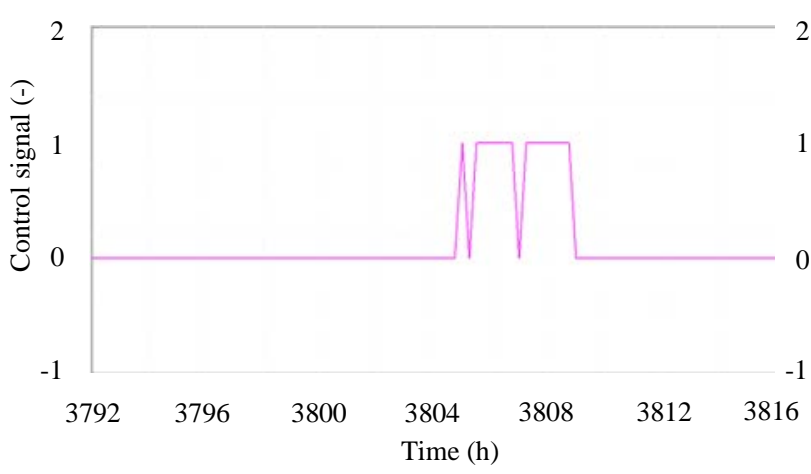

Fig.2 Response of different control systems of the installation (3-way valve, installation and solar circuit pump)

\section{B. Solar collector}

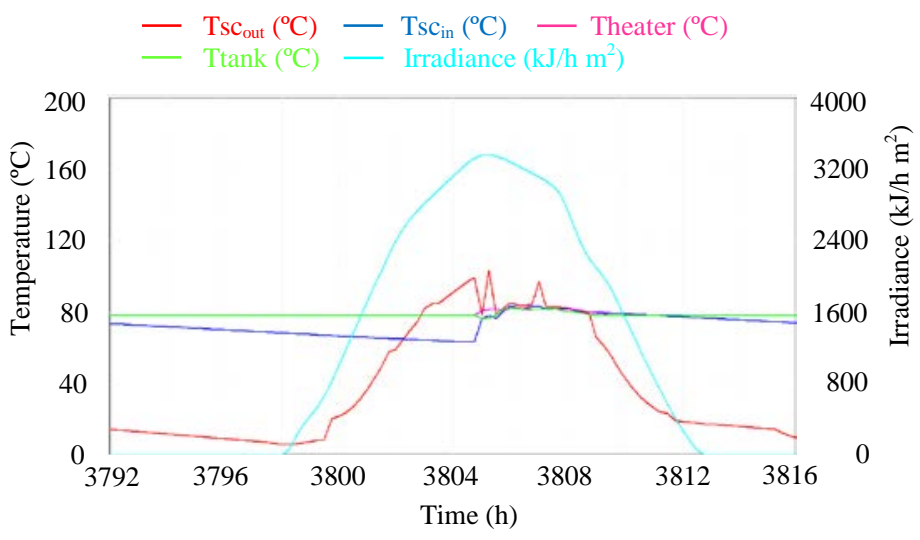

Fig. 3 Changes of temperatures in the solar collectors

To analyze this component begins by observing their behavior from before dawn. It can be observed that while the radiation is zero, or not sufficiently high, the temperature of the solar collector out is equal to room temperature until it reaches 3800 hours (8:00). Then the temperature of the fluid located inside the solar collector begins to rise, at the same time that the temperature and the radiation incident on the collector. When the system detects that it is necessary to activate the absorption machine, the installation starts working, so that TRNSYS performs an energy balance, balancing temperatures generator with solar collector circuit, and giving as a result the initial oscillations which will be explained below.

\section{1) Initial transient phenomenon}

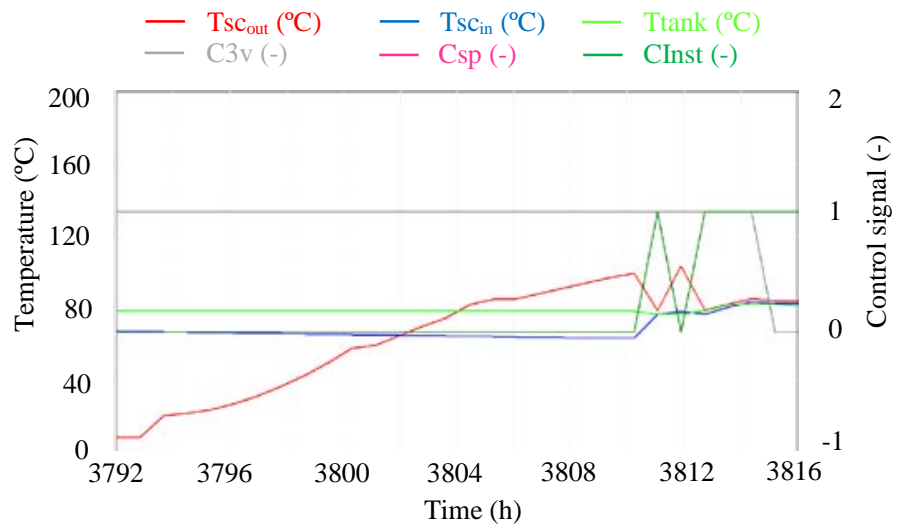

Fig. 4 Control chart evolution during start of the installation. 
During start-up and shut-down operations are observed oscillations that will stabilize after a while. These oscillations occur due to calculation system TRNSYS, the control system implemented, the selected tolerances and the step of time introduced.

In figure 4 have been shown the control signals with the input and output temperature of the solar collector. Analyzing the controls, and knowing that we are in the work schedule of the installation can be seen that the temperature of the room is higher than the target temperature when the control signal of the solar pump takes value 1 , so that the installation starts running. A series of energy balances are performed in installation and in that time step to the room temperature falls below the target temperature, so that the control system considers that the system operation is not necessary and returns to stop. This phenomenon is one of the causes of the oscillations of the initial transient, but there is another phenomenon which we must consider.

As previously stated, for the circuit of solar collector is operating, the inlet temperature to the heat exchanger from the collector must be $4^{\circ} \mathrm{C}$ greater (due to defined tolerances) that the inlet temperature to the heat exchanger from the absorption machine.

During starting of it, and because the solar radiation is not sufficient to raise the fluid temperature necessary, stops the collector circuit, which are represented by the initial transient oscillations occur. So we can say that the last two phenomena are responsible for the oscillations produced in the starting and stopping of the installation. Over time the starting transient state temperatures observed take their operating values.

2) Uncoupled of the input and output temperature of the solar collectors

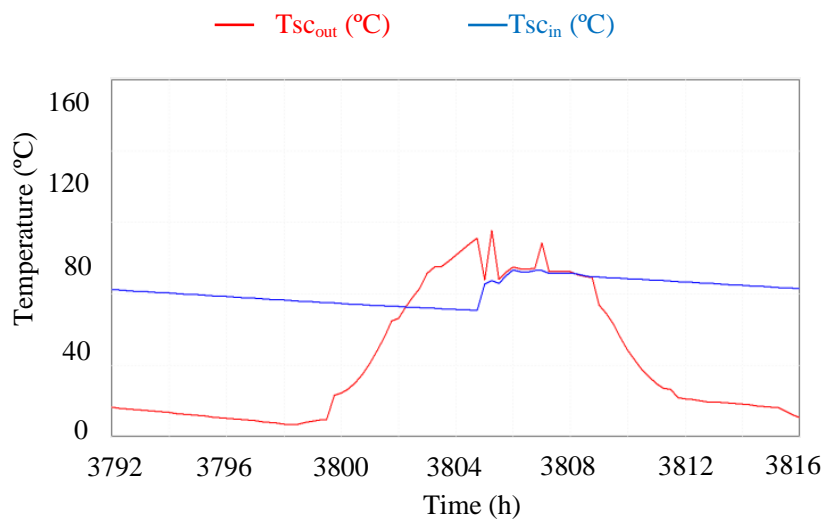

Fig. 5 Effect of temperatures decoupled from solar collectors.

As shown, TRNSYS uncoupled the inlet and outlet temperatures of the solar collectors when there is no flow flowing through it. Thus, the only equilibrium temperatures are searched when the solar circuit is operating. Thanks to separating we can see how the fluid temperature rises inside the collector when solar radiation is provided and does not give any heat to another fluid.

\section{Heat exchanger}

In our system, a heat exchanger operates as Fan-Coil between the house and the absorption chiller.

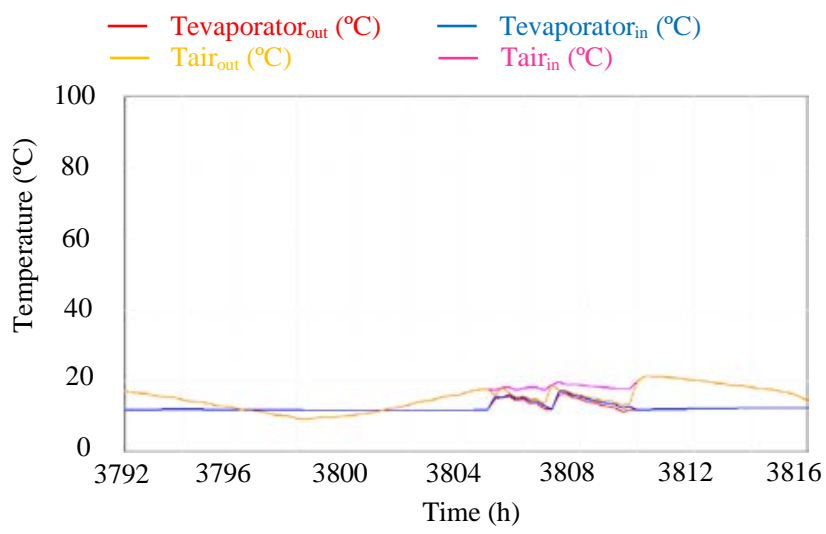

Fig.6 Evolution of temperatures in the exchanger (fan coil)

This exchanger performs the function of Fan-Coil for cooling the room. As in the analysis of the above components, it can be clearly observed a transitional period during startup of the installation. As shown in figure 6 of the evolution of the input and output temperatures fan coil, the two lower temperatures correspond to the temperatures of the current from the absorption chiller. It can also be noted that the temperature change of the cold flow is about $1.5^{\circ} \mathrm{C}$ during the steady period. Furthermore, the temperature change of the air flowing through the fan-coil is 5, thereby producing the cooling of the room.

Another noticeable effect is the rise in air temperature when the installation stops working at 18:00 hours. This indicates that the temperature of air flowing through the Fan-Coil when system downtime is raised to be equal to the temperature inside the house. Similarly, temperatures cold flow (which comes from the absorption chiller) will be equalized when the installation is stopped. This is because the pump that is responsible for circulating the fluid through the cooling circuit is stopped, so that the input and output temperatures will be the same since there is no heat exchange.

In contrast to module TRNSYS responsible for calculating the solar collectors, in this case when there is no flow through the interior of the heat exchangers, temperatures are not decoupled, that is, temperatures input and output of both flows will be equalized. This phenomenon is because through the exchanger no heat input due to radiation or other sources, so that the temperatures are equal.

\section{Tank}

Although there are two deposits in our system, the most important thing to note is that found in the generator circuit, generator tank, whose input and output data shown in the following figure. 


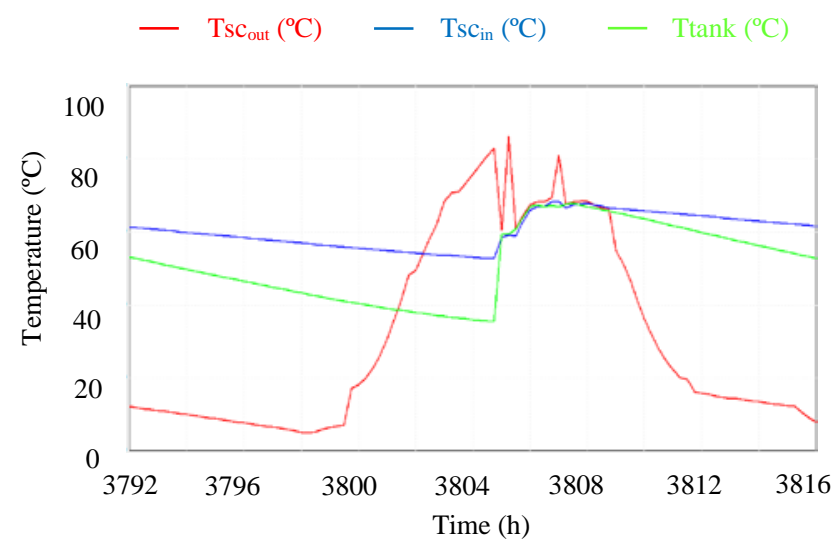

Fig. 7 Evolution of temperatures in the tank generator circuit

As it is shown in figure 7 , both tank temperatures as collectors decrease over night. When it starts to influence solar radiation in collectors temperature of the fluid flowing inside begins to rise (this effect can be observed in the figure 7 , considering the temperature decoupled discussed earlier). Only when the solar circuit starts operating collectors water enters the tank and the temperature rise fan coil, which will remain at approximately the same temperature as the output of the solar collectors while the solar circuit is operating.

\section{E. Boiler}

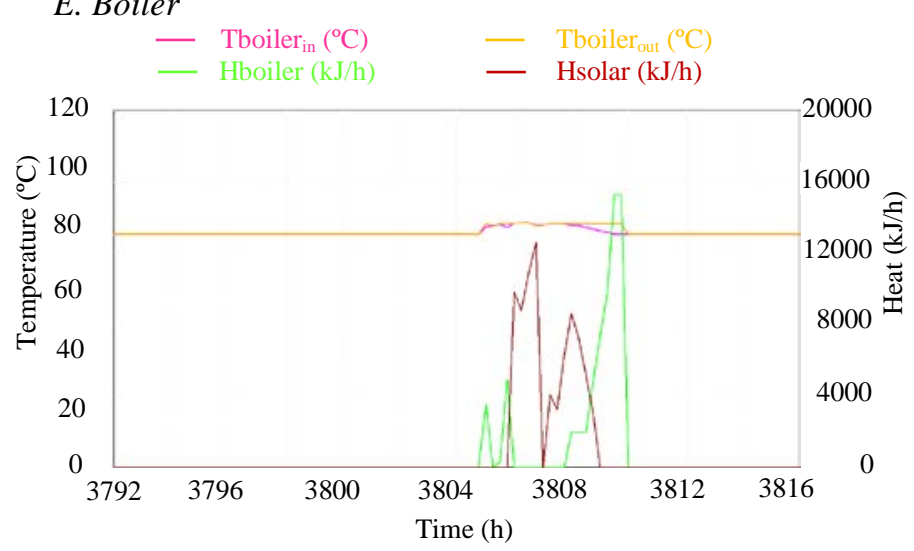

Fig. 8 Evolution of change of temperature in the boiler

To properly analyze this element, it has been superimposed on the figure 8 , the temperature of the fluid flowing through the boiler and the temperature of the solar collectors.

Thus, it can be observed how as the beginning of the day when it is necessary to raise the temperature of a fast way to reach the optimum operating temperature, heat is supplied by the boiler until the temperature of the generator circuit reaches its temperature nominal $82^{\circ} \mathrm{C}$, then, the temperature reached by the fluid flowing through the solar collectors is sufficient for the boiler to be turned off, so that boiler stops. The heat required to maintain that temperature will be provided by both the solar collectors and the boiler, if the solar collectors are not able to reach that temperature by themselves, as the beginning and end of the day, when the radiation is less, boiler provide the necessary heat. It is observed in figure 8 as the heat supplied by the boiler decreases when solar radiation increases.

\section{F. Dry cooling tower}

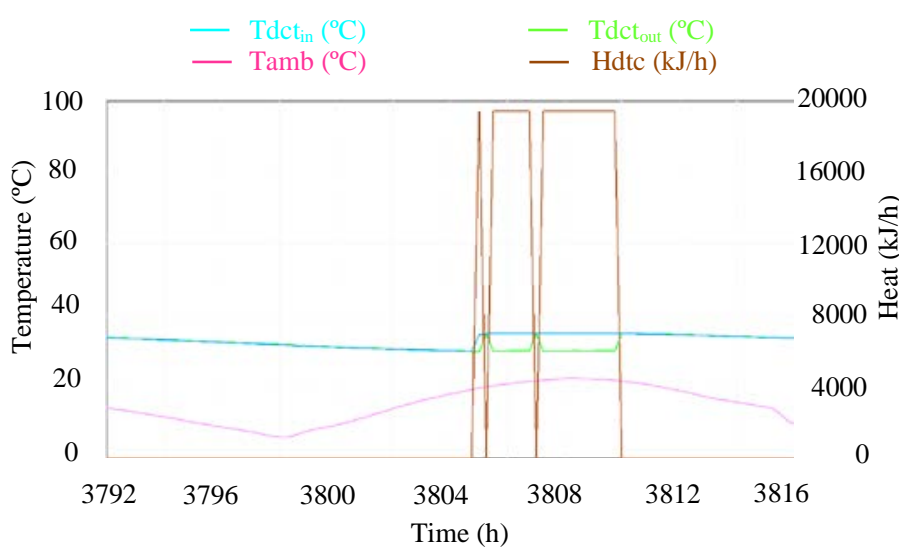

Fig.9 Changes of temperatures in the dry cooling tower (Tdct).

In figure 9, at the start of operation of the installation an initial transient can be observed, as in the above listed components. After this transitional find a change in temperature of $5{ }^{\circ} \mathrm{C}$, thanks to which the cooling of the external circuit occurs. Once the installation stops operating, the inlet and outlet temperatures of the heater will be equalized. This temperature will decrease trying to reach equilibrium with the ambient temperature.

Figure 9 shows also the heat power dissipated by the dry cooling tower, which always works at maximum rated capacity during this day, made some stops due to the shutdown of the installation commanded by the control systems.

\section{G. Absorption Chiller}

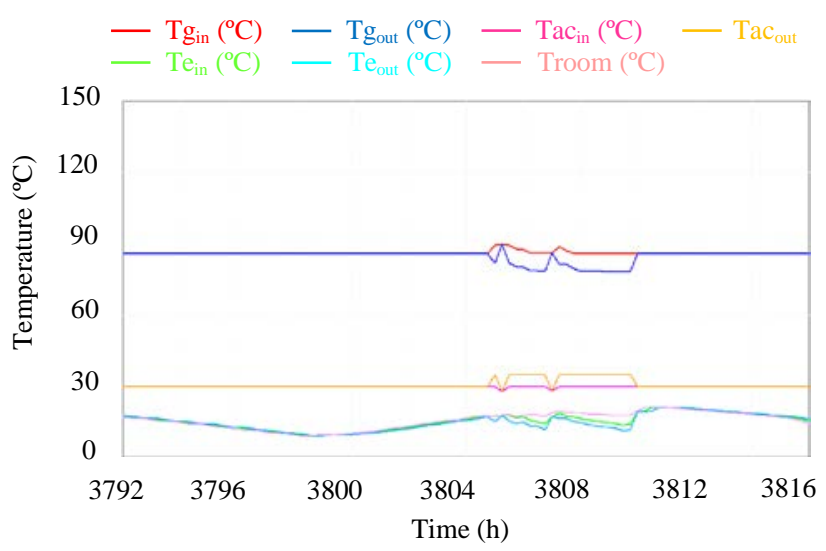

Fig. 10 Changes of temperatures in the absorption chiller, e (evaporator), g (generator), ac (absorber condenser)

In figure 10 the inlet and outlet temperatures of the three circuits of the absorption chiller are showed.

The generator circuit is where the temperatures are higher, the inlet temperature should be around $82^{\circ} \mathrm{C}$. As shown in the figure 10, after the initial transient and once the machine operation has been stabilized, the temperature difference between inlet and outlet is $7^{\circ} \mathrm{C}$. When the machine is not operating both the inlet temperature and outlet are equal. 
The cooling circuit is found in the intermediate temperature range, and the temperature difference between the input and the output is around $5^{\circ} \mathrm{C}$. As in the generator circuit, when the absorption chiller is stopped, the inlet and outlet temperatures will be equalized.

Finally, we found the cooler circuit, which will be responsible for cooling the room and keep it at the desired temperature. The inlet and outlet temperatures of the circuit when the system is not in operation is set equal to the room temperature, because the circuit is in direct contact therewith through the heat exchanger 2 (FanCoil). However, when the facility starts operating, temperatures decrease and a change in temperature of $2{ }^{\circ} \mathrm{C}$ to cool the room air and thus maintain the desired temperature. All oscillations that occur in cooler temperatures circuit will be represented directly on the room temperature as they are directly related. As discussed above, when the installation stops functioning at 18:00 hours, temperatures of this circuit again equated to room temperature.

\section{H. Room temperature}

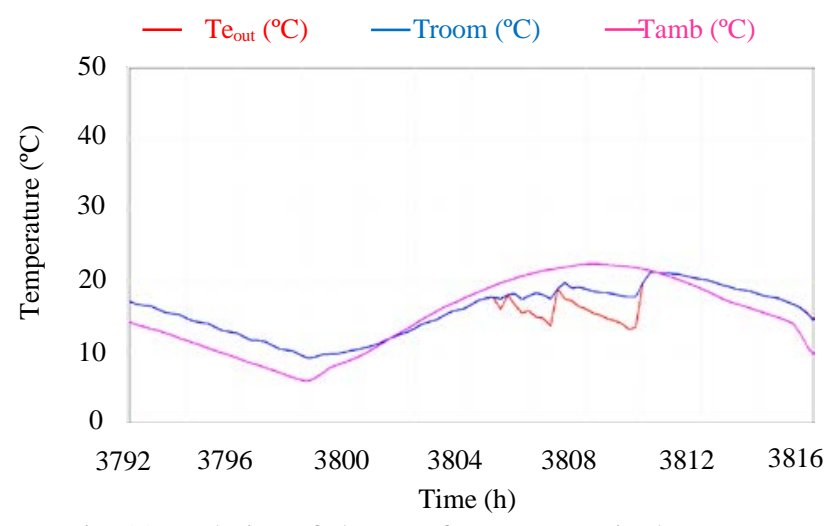

Fig. 11 Evolution of change of temperature in the room

In figure 11 changes in room temperature are showed. Early in the morning it can be observed how the room temperature rises due to increased ambient temperature and incident solar radiation. The tendency of increase is not the same due to the thermal inertia produced by the insulating walls and the room. When the room temperature is higher than the target temperature, the installation starts running, and after passing the transitional start keeps the room temperature constant until the stop time (18:00) comes. At that time the temperature of the room rises again, seeking balanced with the outside temperature. As the beginning of the day, it is noted that the room is cooled to a temperature below room rate due to the thermal inertia of the room.

\section{Conclusions}

In this paper a dynamic model of a solar cooling system has been presented. The model was developed using TRNSYS. This program helps understand the functioning of HVAC systems and helps to design through simulations. Thus, the model presented in this work will be used for the evaluation of further investigation and improvements in the installation.

In the present work, it has been analyzed separately the behavior of each of the components of the installation and it have been shown the differences between the temperatures of input and output of each of them, discussing and justifying the phenomena that appear in each one of them. According to the results discussed in the previous section, in the figures can be observed two clearly differentiable periods, an initial transition period and a period of stabilization.

\section{Acknowledgments}

This work is part of the University of Jaén Research Support Scheme and it is entitled: "Analysis of optimisation of renewable sources for cooling purposes. Applications in the province of Jaén”. (Code uja_07_17_01).

\section{References}

[1] EPBD, 2010. Directive 2010/ Brussels, 30 March./EU of the European Parliament and of the Council of on the Energy Performance of Buildings. http://register.consilium.europa.eu/pdf/en/10/st05/st05386ad01.en10.pdf.

[2] Nielsen, M.V., Svendsen, S., Jensen, L.B. Quantifying the potential of automated dynamic solar shading in office buildings through integrated simulations of energy and daylight. Solar Energy, 2011, (5), pp. 757-768.

[3] Official Web of the company dedicated to power transmission and the operation of electrical systems in Spain. http://www.ree.es .

[4] K.E. Herold, R. Radermacher, S.A. Klein, Absorption Chillers and Heat Pumps Book 329 pages. CRS Press LLC, 2000 N.W, 1996.

[5] Kaynakli O, Kilic M. Theoretical study on the effect of operating conditions on performance of absorption refrigeration system. Energ Convers Manage 2007, 48, 599607.

[6] Li ZF, Sumathy K. Technology development in the solar absorption air conditioning systems. Renew Sust Energ Rev 2000, 4, 267-93.

[7] P. Kohlenbach, F. Ziegler, A dynamic simulation model for transient absorption chiller performance. Part I: the model, International Journal of Refrigeration 2008, 31, 217-225.

[8] F. Assilzadeh, S.A. Kalogirou, Y. Ali, K. Sopian, Simulation and optimization of a $\mathrm{LiBr}$ solar absorption cooling system with evacuated tube collectors, Renewable Energy 2005, 30, 1143-1159.

[9] H.M. Henning, Solar assisted air conditioning of buildingsan overview, Applied Thermal Engineering 2006, 27, 17341749.

[10] C. Monné, S. Alonso , F. Palacín , L. Serra. Monitoring and simulation of an existing solar powered absorption cooling system in Zaragoza (Spain). Applied Thermal Engineering, 2011, 31, 28-35.

[11] U. Eicker, D. Pietruschka. Design and performance of solar powered absorption cooling systems in office buildings, Energy and Buildings, 2009, 41, 661-673.

[12] http://andyschroder.com/rotartica.html.

[13]TRNSYS 16 Documentation, A Transient Simulation Program. Solar Energy Laboratory, University of Wisconsin, Madison, 2006. 